\title{
Application of sustainable development principles in foreign language education
}

\author{
Elena Makarova* \\ Ural State University of Economics, 8 Marta Str., 62, 620144 Ekaterinburg, Russia
}

\begin{abstract}
The article is aimed at identifying sustainable development principles and their application in foreign language education process in the context of a Russian university. The relevance of two basic elements of quality education, such as educational content and the learning environment to sustainable development principles' development are considered. The results of the survey aimed at identifying students' perception of these two are presented. The analysis of effective ways of developing students' competences related to English language learning and cross-cultural aspects, compatible with sustainable development, is presented. Implications of students' involvement into extra-curricular activities and events designed and held on the interdisciplinary basis and aimed at reaching sustainable development objectives are suggested for practical implementation.
\end{abstract}

\section{Introduction}

The key role of education in creating sustainable world which is the main purpose of sustainable development has been widely accepted. This view is shared by international community, government officials, academic and teaching staff employed in educational institutions of different types. In order to oobtain knowledge and acquire skills which are vital for understanding the concept of sustainable development and applying its principles to real life a learner must have access to quality education, which goals and elements have been the subject of numerous studies and debates for the last decades in different contexts $[1,2,3]$. According to UNESCO, education for sustainable development as an integral part of quality education is "holistic and transformational education which addresses learning content and outcomes, pedagogy and the learning environment" [4].

Integrating the concept of sustainable development into education demands concentrating on the process of learning and the outcomes reached by learners. The emphasis must be made on interdisciplinary curriculum design, which provides them with knowledge from different fields [5]. Special attention is paid to the learning content which covers topics related to both local and global critical issues which accompany nature conservation activities, refer to biodiversity, modern economic processes, challenges which culturally diverse communities face [6]. The learning outcomes don't imply only knowledge, but also skills which learners acquire during sustainable development education

\footnotetext{
* Corresponding author: makarovayn@mail.ru
} 
process. They are the core competences necessary to help learners achieve success in various life contexts. Among the most demanded for both professional and social life in the modern world are the skills known as soft skills, such as willingness to accept responsibility, ability of critical thinking and problem solving, readiness to work in a team and collaborate decision making, and so on. These goals can be achieved on the basis of applying effective and reliable educational methods and a learner-cantered approach, which combines learners' interest to the educational process and their responsibility for its results. Pedagogical approaches and methods aimed at encouraging young generation to act for sustainability are actively discussed in modern literature [7]. In modern conditions hybrid model of teaching in physical and on-line environments has proved its reliability. Sustainable development processes in education are accompanied by extensive use of elearning technologies and latest digital technologies. Their potential for promoting education for sustainable development and providing learners with opportunities of gaining knowledge and acquiring skills for leading sustainable lifestyle is recognized and proved [8].

Integrating education for sustainable development principles into higher education has been studied in various aspects. The majority of authors acknowledge the importance of the universities' role in implementing sustainable development policies. However, some studies argue that this implementation inevitably brings certain challenges which modern higher educational institutions have to face [9]. Studies focusing on students' perception of higher education for sustainable development's learning environments definitely arouse much interest. Maurer and Bogner report on 464 freshmen perception of both environmental education and education for sustainable development. The analyses of sustainability concepts and their perceiving by the students demonstrate a significant discrepancy [10]. The majority of research consider the issue of integrating sustainable development policies into higher education in connection with higher educational institutions' activities [11]. Special attention in recent studies is paid to university educators' engagement in educational sustainable development processes. Academic staff training and participating in professional development programs are considered to be crucial for education for sustainable development successful integration [12]. Another subject for consideration and debate in the field of educating educators themselves concerns the need for universities' collective efforts and activities aimed at achieving this goal. Collaboration of the Baltic and the Mediterranean regions in introducing and promoting education for sustainable development principles in higher education serve as a good example of effective cooperation in this field [13].

As initially the concept of education for sustainable development was focused on the learners' developing knowledge and skills in the field of nature conservation and interaction between natural environment and society, a lot of studies the most part deal with environmental education and related issues [14, 15, 16, 17]. Gradually education for sustainable development started to concern with the ways of predicting and solving social environmental problems. Today more and more academics and educators apply its principles when teaching different disciplines, such as mathematics [18], history [19], and foreign languages [20]. Analysing environment not only in ecological but economic, social and cultural aspects affects learners' better understanding of modern world's and diverse societies' interests and needs.

Language and foreign language education for sustainable development has been given considerably less attention in modern literature in comparison to the other learning areas. Being a part of culture and playing a significant role in building human relationship, language can be a key instrument for tackling global problems and challenges. Within the area of foreign language education for sustainable development programs a learner can acquire a wide variety of skills necessary for establishing effective international 
communication and cooperation. Foreign languages knowledge as well as awareness of differences in national beliefs and behaviours, which are gained in the process of learning a foreign language, are essential for sustainable development of the modern world with its intensive migration processes. Literature review shows that goals of sustainable development can't be attained without solving problems arising in multilingual educational contexts [21].

English as a Lingua Franca and global means of communication enables representatives of different ethnic groups and cultural experiences to socialize and find common ground. As a result, English as a foreign language education process provide the basis for global society sustainable development.

\section{Materials and methods}

The aim of the study is to analyse the two elements of quality education - content and learning environment, and reveal their relevance to the principles of education for sustainable development considering the examples from the English language teaching and learning experiences in the context of a Russian university of Economics. In order to gain better insight into the effectiveness of each element, qualitative research tools have been used. Both curricular and extracurricular students' activities have been observed, analysed, interpreted and described. The article also provides results of the survey which allows identifying second year students' (42 learners) and third year students' (31) perception of the university's curriculum content and the learning environment.

\section{Results and discussion}

\subsection{Content}

As it has been mentioned above, originally education for sustainable development was concerned with the knowledge and skills in the field of ecological problems and nature conservation. "Green" issues have influenced the curriculum design in many areas of study. Teaching concepts related to natural environment are studied in different disciplines, including foreign language education field. This topic is relevant for the students of a higher educational institution as it addresses crucial issues of modern world which students have already faced in everyday life and will have to seek their solutions in perspective. Educational programs realized by foreign languages departments contain teaching materials aimed at students' obtaining and improving knowledge on the topic, including major ecological problems such as global warming and greenhouse effect, water, land and air pollution, overpopulation, depletion of natural recourses, and the others. The emphasis is made on the reasons and consequences of the major current environmental issues, as well as their prevention and reduction measures' development and introducing. Ways of improving the relationship between man and nature are discussed in detail. Not only the content of the curriculum is worth mentioning but also tasks design and forms of students' curricular activities. The study of the content connected with environmental problems allows to apply a wide range of exercises and tasks within communicative foreign language teaching approach. Learners work with written and oral texts, perform exercises aimed at consolidating lexical material, develop reading, speaking, listening comprehension and writing skills. The study of this topic allows using such forms and methods as oral presentations, projects, discussions, round tables, case studies, web-quests. Writing an essay, which is a mandatory part of training within the framework of nature conservation topic, develops both an independent creative approach to understanding the problem posed, 
and improves the learners' skill of expressing their own thoughts and opinions in writing by means of a foreign language. The results of the survey prove that the absolute majority of second year students $(95 \%)$ find discussion of issues and concepts referring to natural environment important, interesting and relevant. The survey results also show that about $80 \%$ agree that green living approach contributes to sustainability and efficient resources usage. Moreover, about $60 \%$ of the respondents admit that classroom discussions as well as working on group and individual projects made them realize the significance of going green as well as made them think about more sustainable way of living and being more sustainable in their daily routine. These results correlate with the data presented by Gratiela and Saraçl, who report on positive relation between environmental education's perception, attitude and students' behaviour [22].

Another academic content taught to third year students in English refers to crosscultural communication field. All the students learning English are trained to perceive and understand different societies and lifestyles, as foreign language learning in general implies accepting concepts of a foreign culture. This course exposes university students to a wide variety of social and cultural topics, such as "Elements of Culture", "Different styles of communication", "Cross-cultural negotiations" and many others. Taking the course students learn to build up cross-cultural interaction both within the framework of lectures and seminars, and fulfilling work on individual and team project assignments. Due to the foreign students' presence in class a unique real cross-cultural classroom environment is created. Discussions and views' exchange promote Russian and international students' acquiring skills necessary to overcome cultural and social barriers. This contributes to the formation of the intercultural communicative competence which is required for young adults' better understanding principles of living in a global world and implementing sustainable development policies effectively. An important aspect that accompanies the study of other countries' cultures is fostering a respectful and tolerant attitude to different values and behaviours. Intercultural communicative competence is highly valued in global teams where students are very likely to find themselves in a few years. The results of the survey demonstrate students' interest and readiness to different cultures' discovery on the basis of the knowledge they have gained during this course of study (95\% of third year students). The respondents $(72 \%)$ are also sure that the communication skills they have acquired being in the international classroom environment will be helpful for their future professional career in the globalized working surroundings. About $60 \%$ of the students admit that they have become more open and tolerant to the "others". About $30 \%$ of the respondents admit that they knew very little about how to deal with cultural differences before attending the course and would like to learn more. These answers go in the agreement with the results presented in other studies and demonstrate the demand for practicing modern university students' cross-cultural awareness [23].

\subsection{Learning environment}

Significance of foreign language education for achieving sustainable development goals can be demonstrated by applying transdisciplinary approach and creating effective learning environment with interaction of major for university of economics educational fields with the English language. The foreign languages department, along with the other university departments trains bachelors and masters for work in many sectors of local and global economy. Apart from gaining English language knowledge and skills the task is to help young adults succeed in the chosen professional career. Therefore, the fields of students' major studies are definitely taken in consideration in organizing both curricular and extracurricular activities. The foundation for effective work is in long-term cooperation of foreign languages departments with the teaching staff of different university departments 
training students in such fields as marketing and international management, global economy and international economic activities and the others. When acquiring the English language and developing linguistic competence students successfully apply their knowledge gained from the study of their major fields' disciplines.

Another distinctive feature of university learning environment concern forming learners' research competence in the process of teaching a foreign language. The absolute majority of activities and events aimed at its formation are carried out in cooperation with the university departments of management and economics. Among the department's extracurricular activities held in English every academic year are the following:

1. Annual scientific conference for students of 1,2,3 and 4th year. The conference sections and topics of students' oral presentations and papers are preliminary discussed with the university departments' teaching staff and are related to the students' major disciplines. "Green Economy" and "Russia in the global world: challenges of the 21st century" conferences are the examples of the events which cover issues related to the curriculum and allow students apply English language knowledge as a tool for sharing ideas within the limits of their professional area of competence.

2. Extra-curricular round tables are held twice a semester. Teaching academic discussions' and round tables' vocabulary help learners introduce and support their points of view, communicate with the other participants of the round table effectively.

3. Holding science international competition "Socio-cultural links as the basis for trust economy".

4. English-language teachers' guidance on students' writing and publishing scientific articles in English.

5. English-language teachers' assistance in students' preparation for participation in the ESP contests held in Russian and foreign universities.

Ectara-curricular activities are aimed at developing students' professional competencies, foreign language competence, research competence and contributes to the development of learners' soft skills, such as effective communication, teamwork, decision making, critical thinking ability and the others.

\section{Conclusion}

Among basic elements affecting the quality of education two are considered to be crucial. They are educational content and the learning environment. Proper curriculum design as well as arranging effective learning environment prove foreign language education efficiency for achieving sustainable development goals. Including into foreign language curriculum materials and tasks related to natural environment, social and intercultural communication enables students' better understanding of fundamental principles of sustainability and making sustainable lifestyles changes, their being tolerant to the other cultures and getting prepared to work and live in a globalized context. The analyses of educational content and the learning environment in the context of English as a foreign language education and evaluation of the learners' experience in extracurricular activities prove the relevance of foreign language education for sustainable development principles' introduction and promoting. The results of the survey allow making a conclusion about students' positive attitude to sustainable development policies as well as their high potential to develop and apply foreign language knowledge and a variety of skills to deal with challenges of the modern global world. 


\section{References}

1. N. S. Necheukhina, V. S. Matveeva, E. N. Makarova, I. A. Babkin, Proceedings of 2017 IEEE 6th Forum Strategic Partnership of Universities and Enterprises of Hi-Tech Branches (2018)

2. R. A. Madani, HES, 9 (2019)

3. N. Morchid, IOSR-JRME, 10 (2020)

4. What is Education for Sustainable Development? https://en.unesco.org/themes/education-sustainable-development/what-is-esd

5. K. Holley, Oxford Research Encyclopedia of Education (2017)

6. J. Laurence, K. Schmid, M. Hewstone, J. Ethnic Migrat Stud, 45 (2019)

7. J. Fedosejeva, A. Boče, M. Romanova et al., JTEFS, 20 (2018)

8. J. Bolmsten, M. E. Manuel, Edu Tech R\&D, 7 (2020)

9. M. Barth, J. M. Timm, J. Soc. Sc., 7 (2011)

10. M. Maurer, F. X. Bogner, PLoS ONE, 14 (2019)

11. R. Howarth, T. Ndlovu, S. Ndlovu et al., Emerald Open Research, 1 (2019)

12. I. Mulà, D. Tilbury, A. Ryan et al., Int J Sustain High Educ, 18 (2017)

13. M. Scoullos, V. Malotidi, P. Lindroos, S. Suomalainen, Int J Sustain High Educ, 18 (2017)

14. K. Van Poeck, Environ Educ Res, 21 (2015)

15. T. Braun, R. Cottrell, P. Dierkes, Environ Educ Res, 24 (2018)

16. B. S. R. Grimwood, M. Gordon, Z. Stevens, J Experiential Educ, 41 (2018)

17. B. Munge, G. Thomas, D. Heck, J Experiential Educ, 41 (2018)

18. N. Pasichnyk, R. Rizhniak, I. Krasnoshchok et al., Univ J Educ Res, 8 (2020)

19. D. Hendriawan, M. Ali, Rusman, J Phys Conf, 1179 (2018)

20. T. Zygmunt, Discourse and Communication for Sustainable Education, 7 (2016)

21. N. Toppo, Md. M, Rahman, Problemy Ekorozwoju, 15 (2020)

22. B. D. Gratiela, S. Saraçl1, Sustainability, 11 (2019)

23. E. Nteliou, O. Kehagia, IJLTIC, 4 (2016) 